\title{
Applying the TRIZ Systematic Innovation Method to Improve Short Circuit Devices
}

\author{
Ying-Hsiang Lin ${ }^{1}$, Shang-Pin Li ${ }^{1, *}$, Chien-Yu Lu${ }^{1}$, Ruey-Gwo Chung ${ }^{2}$ and Der-fa Chen ${ }^{1}$ \\ ${ }^{1}$ Department of Industrial Education and Technology, National Changhua University of Education, Changhua, Taiwan, R.O.C \\ ${ }^{2}$ Hsiuping University of Science and Technology, Taichung, Taiwan, R.O.C \\ ${ }^{*}$ Corresponding author
}

\begin{abstract}
A short circuit protector will quickly switch off power in case of an overload or short circuit fault in order to quickly isolate or eliminate the fault. This research uses the contradictions matrix of the TRIZ innovation theory and 40 innovation principles to innovate and improve the product. The improved short circuit protection employs an optical coupler for detection, and the control circuit is triggered synchronously at the moment when a short circuit happens so as to cut off the power and sound a buzzer alarm. The response time is 14 milliseconds, which is faster than the response time (0.1 seconds) of tripping a fuse circuit breaker so as to achieve circuit protection.
\end{abstract}

Keywords- short circuit protection device; TRIZ; contradiction matrix

\section{INTRODUCTION}

A switch device plays an important role in the switch-on and switch-off of a circuit in a power distribution system. To ensure the stability of the power system and personnel and electricity safety, a short circuit protector can quickly switch off the power in case of an overload or a short circuit fault to quickly isolate or eliminate the fault. Therefore, a circuit breaker should have enough capacity to switch on or switch off the distribution system connected to the breaker under any load condition and be able to bear the fault current of symmetric and asymmetric short circuits in a short time and a load current in a long time (ANSI standard C37.100, 1992) [4].

The Theory of Innovative (Inventive) Problem Solving is referred to as TRIZ (Sung, 2009). The Theory of TRIZ was proposed in 1946 by G. S. Altshuller, a former Soviet Union inventor, who is also regarded as the father of TRIZ. Altshuller started to lead the research institutes of former Soviet Union universities and enterprises to form TRIZ research groups starting in 1946. They analyzed nearly 2.5 million pieces of global high-level invention patents and put forward the basic theory on the problem of inventions based on dialectical materialism and systematic thoughts. Currently, many scholars have been devoted to the research of TRIZ, such as Chang and Lin (2013) and Chang et al. (2015). This present research uses the contradiction matrix, 39 engineering parameters, and 40 invention principles in the Theory of Inventive Problem Solving (TRIZ) to find out the points that need improvement and then improve them.

\section{RESEARCH METHOD}

\section{A. Research Process}

As shown in Figure 1, after identifying the issues of an object, we need to find out the issues and the technical contradictions. After learning the technical contradictions, we then can develop the $39 \times 39$ contradiction matrix in search of the 40 inventive principles that can possibly solve the technical contradiction. Next, the feasible 40 inventive thinking solutions and logic thinking are employed to consider the listed programs and select the most appropriate solution to solve the problem.

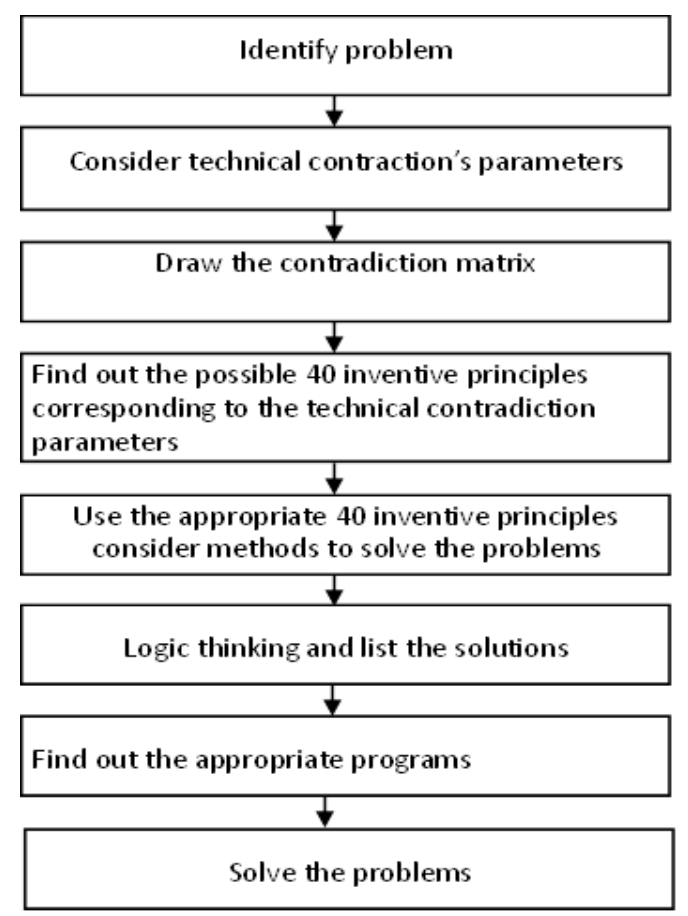

FIGURE I. RESEARCH FLOWCHART

\section{B. Contradiction Matrix}

Altshuller observed each technical contradiction and developed a system accordingly. The first system regarding innovation and invention is known as the contradiction matrix. When studying patents, he would confirm and summed up the 
technical contradictions and the applied innovative inventive principles for this patent. Based on the summaries of a large number of patents, he summed up 39 engineering parameters and 40 innovative inventive principles, and developed the $39 \times 39$ matrix , which is a matrix using i to represent the improved characteristic and $\mathrm{j}$ to represent the avoidance of worsening result. Each box grid represents a type of inventive problems, and each inventive problem has corresponding $i$ and $\mathrm{j}$ coordinates. In the box grid of specific $\mathrm{i}$ and $\mathrm{j}$, there are identification codes of inventive principles to solve the problems [8].

\section{40 Inventive Principles}

40 principles provide TRIZ users a way of thinking from principle to application. Each inventive principle is a simple basic concept, and the derived thoughts from the principle can cover a wide range. Different principles' layers and details can produce different architectures and contents. Each principle and thought can empower the innovator with new answers, "think about each principle and then find out the answer"[5],[6].

\section{Actual CAse Of Improved Design}

\section{A. Improvement of the Design of an Innovative Short Circuit Protection Device}

A short circuit protection device of a student low-voltage distribution practice facility includes a power supply input terminal and output terminal, a circuit breaker unit, a control unit, and a detection unit. When the detection unit detects a surge in the short circuit current, a Silicon Controlled Rectifier (SCR) is triggered synchronously to make a conduct or a nonconduct anode and cathode. In a normal power supply, the anode and cathode of SCR will remain in a conduction state; and the anode and cathode of SCR will quickly switch off when a short circuit happens. At that time, the LED light turns on to indicate a short circuit has occurred in two connected phase sequence terminals, while at the same time an alarm rings to facilitate the debugging by students. Power failure will not affect other power supplies and the practice of other students either. Compared with the traditional halogen lamp short circuit protection device in a low-voltage practice facility, this new type of short circuit protection device can add a load to form a closed loop for operation. The use of electronic switch components in the detection unit will fasten the response time, with no impact on the non-fuse breaker set in the front of the power supply terminal, so as to increase power supply stability. When circuit parameter values are changed in this research, different use purposes of electricity protection can be reached, such as the electricity being divided into single-phase AC110V, AC220V, and three-phase AC220V power supply.

\section{B. Technical Contradiction of New Short Circuit Protection Device}

When students work on low-voltage distribution in a lowvoltage practice facility, the facility has a traditional halogen lamp short circuit protection device that will impact the nonfuse breaker set in front of the power supply terminal so as to increase power supply instability. Power failure will affect other power supply and the work of other students. Technical contradiction of a short circuit protection device lies in "Speed" and "Temperature".

\section{Development of Contradiction Matrix}

As shown in Table 1, the appropriate i (improved characteristics) and $\mathrm{j}$ (results of avoided worsening) are found in the matrix, "Speed" in column 9 corresponds to "Temperature" in line 17, and the frame intersecting at the column and line represents suggested principles that can solve the current contradiction.

\section{TABLE I. CONTRADICTION MATRIX}

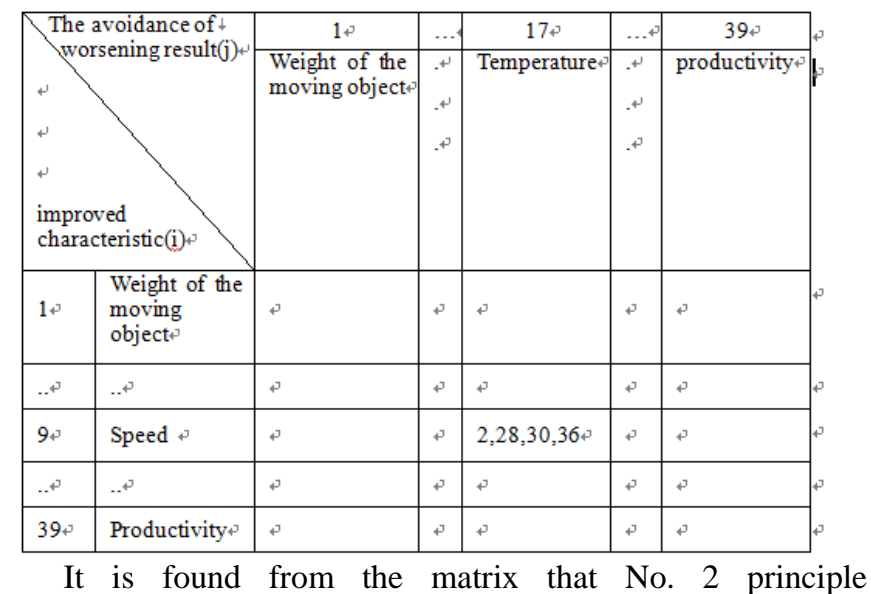
"Separation", No. 28 principle "Replace field system", and No. 36 principle "Phase Change" among the 40 invention principles can be applied mechanically, which is the best suggestion for the improvement of current technologies.

The contents of No. 2 principle "Separation" are as follows.

1. Extract, remove, and separate what is not wanted from one object.

2. Extract, remove, and separate what is wanted from one object.

This principle is used in a short circuit protection device to remove the original halogen lamp short circuit protection device and import a new short circuit detection unit to improve upon it. The contents of No. 28 principle "Replace Field System" are as follows.

\section{Use another kind of sensing method.}

2. Use electric field, magnetic field, or electromagnetic field to interact with an object or system.

3. Use mobile field to replace static field, and structured field to replace unstructured field.

4. Use field and connect particle, object, or system that can interact with the field.

This principle reduces unnecessary waste to increase the efficiency of a short circuit protection device. The contents of No. 36 principle "Phase Change" are as follows. 
1. Use the phenomena that have happened in the process of phase change.

According to this principle, we are required to remove useless aspects of a short circuit protection device so as to realize necessary functions.

\section{Thinking and Improvement}

We first start the exploration from the perspective of No. 2 principle of "Separation". What we do is assume how the short circuit protection device works when the short circuit occurs. The halogen lamp short circuit protection device is used, but with no good effect; therefore, we consider the newly designed short circuit detection unit to be added. Next, No. 28 principle of "Replace Field System" is considered, and the principle is to reduce unnecessary waste so as to increase the effectiveness of the short circuit protection device. The original halogen lamp short circuit protection device will cause the power failure of works of the students when a short circuit occurs, causing a lot of waste. Lastly, No. 36 principle "Phase Change" is considered to remove the old halogen lamp short circuit protection device (as shown in Figure 2).

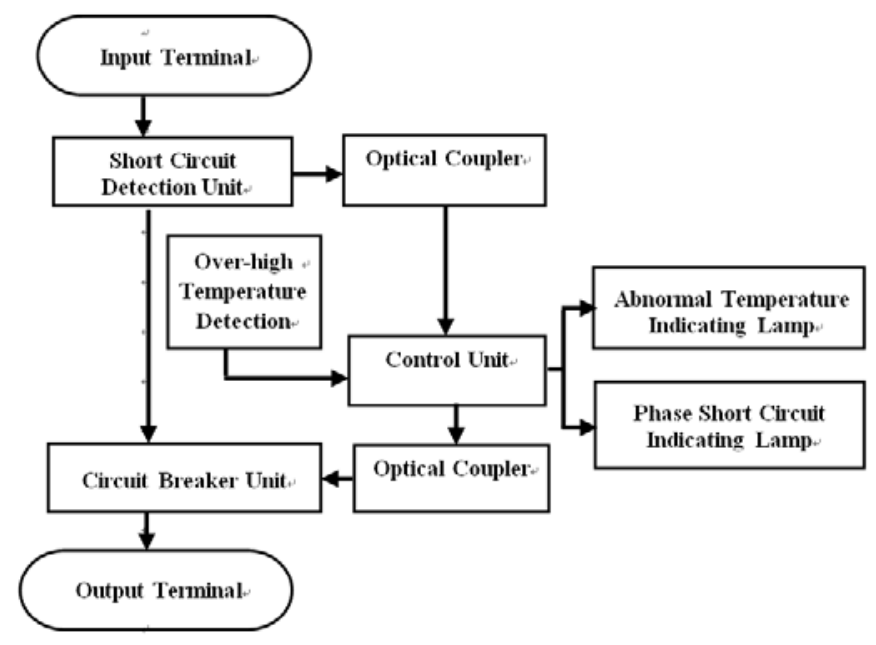

FIGURE II. NEW SHORT CIRCUIT PROTECTOR

\section{E. Summary}

The short circuit protection circuit uses an optical coupler for detection, and the control circuit is triggered synchronously at the moment when a short circuit happens to cut off the power and a buzzer alarms. Its characteristic is that the response time is only 14 milliseconds, which is faster than the response time (0.1 seconds) of tripping a fuse circuit breaker, thus achieving circuit protection. The surge in short circuit current will have no impact on the non-fuse breaker set in the front when a short circuit occurs, and it will not affect other power supply and the works of other students either. The function of a short circuit protection device is to indicate the phase sequence of a short circuit to facilitate the debugging by students; it also provides an over-high temperature circuit protection. When the temperature of the gold aluminum shell resistance rises to 60 degrees or above, the three-phase circuit will trip, the abnormal temperature indicating lamp will turn on, and the buzzer alarm will ring. In the circuit design, the design cost is low, and so it is suitable for mass production and can be applied to a short circuit protection device of lowvoltage practice facility for industrial wiring by higher vocational college students. It can also effectively improve the equipment environment of a factory and distribute power for industrial wiring. When a fault occurs, the students can learn the cause of the fault immediately so as to enhance their works and ability at circuit debugging.

\section{CONCLUSIONS}

TRIZ innovation theory can be applied in a lot of things, not just only products but also service. Regardless of what the industry, problems will arise inevitably. The understanding and learning of TRIZ is like the opening of an extra window, and you can have a wider vision than others. It can guide us to quickly find where the problem lies, to analyze problems, identify the key, and then employ the thinking logic of TRIZ before taking appropriate solutions. The improvement and design of this research have helped the feasibility of problem solving, from problem thinking to the process of solving problems, through the use of a design process method and logical thinking concept provided by TRIZ. The contributions of this research with the use of TRIZ are as follows.

1. The literature review shows that TRIZ is a kind of systematic theory with strong logical thinking, making persons with no advance knowledge of TRIZ quickly understand and enter into a situation.

2. The $39 \times 39$ contradictions matrix and 40 invention principles used in this research are breakthrough solutions to problems in TRIZ, making readers clearly understand the process of problem solving with this method.

3. For the case of improvement, a lot of thinking in relation to logics is provided, which can be applied to other design improvements with the use of logical thinking.

4. A new type of short circuit protector is designed herein through the renovation and innovative concepts developed in this research, which should smoothly improve practical functions.

\section{REFERENCES}

[1] ANSI standard C37.100, Definitions for power switch, 1992.

[2] Chang, C. P., Lin, Y.H.,” Innovative Structure Improvement of A Glare Shield”, Applied Mechanics and Materials, Vols. 321-324, pp 42-45, 2013.

[3] Chang, C. P., Lin, Y.H. and Lu, C. Y., "Applying TRIZ Systematic Innovation Method to Improve Urinals”, Advances in Engineering Research, Vols. 22, pp 793-795, 2015.

[4] S. Lotfifard, J. Faiz, M. Kezunovic, "Over-current relay implementation assuring fast and secure operation in transient conditions," Electric Power Systems Research, vol. 91,pp. 1-8, 2012.

[5] Dana W. and Clarke, Sr. "40 Principles Extended Edition: TRIZ Keys to Technical Innovation”, Technical innovation center, pp.11-13, 2005.

[6] Dana W. and Clarke, Sr., "40 Principles Extended Edition: TRIZ Keys to Technical Innovation”, Technical innovation center, pp.17-18, 2005.

[7] M.H. Sung, Systematic innovation : An introduction to TRIZ, Tingmao Publish Co., 2009.

[8] T. L. Chiang, Theory of Inventive Problem Solving, pp.40-48 Yuhe Publish Co., 2008 